\title{
Empirical Study on the Effects of Leader's Verbal Communication Style on Employee's Job Satisfaction
}

\author{
Wenchen Guo, Tingting Li, Ning Wu \\ Faculty of Management and Economics, Dalian University of Technology, Dalian, China \\ Email:guowch@dlut.edu.cn, femtdcqt@163.com
}

Received 23 November 2015; accepted 25 December 2015; published 28 December 2015

Copyright (C) 2015 by authors and Scientific Research Publishing Inc.

This work is licensed under the Creative Commons Attribution International License (CC BY). http://creativecommons.org/licenses/by/4.0/

(c) (i) Open Access

\begin{abstract}
This article investigates the potential mediating role of work engagement/job burnout in the relationships of leader's verbal communication style and job satisfaction. Results suggest that autocratic verbal communication style leads to low job satisfaction. To the contrary, supportive verbal communication style results in high job satisfaction. Furthermore, work engagement plays an intermediating role between leader's verbal communication style and job satisfaction. Although job burnout plays a mediation role between autocratic verbal communication style and job satisfaction, the mechanism is non-existent between supportive verbal communication style and job satisfaction. The article revealed the significance of leader's verbal communication style, as well as the diversities, which affected job satisfaction and thus influenced job performance.
\end{abstract}

\section{Keywords}

Leader's Verbal Communication Style, Job Satisfaction, Work Engagement, Job Burnout

\section{Introduction}

Communication is important and necessary in a broad sense. One cannot leave communication; any act or any behavior one exhibits is some form of communication or another. Communication is a vehicle and central element in an organization as it serves many functions in organization. A number of empirical studies support this emphasis on the communication process, suggesting that from a third to two thirds of a manager's time is spent in communicating with subordinates, predominantly in a face-to-face mode (Jablin, 1979) [1]. Just about the one thing almost all these authorities agree upon, however, is that effective leaders are also effective communicators. The role of communication in who becomes a leader cannot be refuted. Communication is a general conception, 
and the communication style is concluded from the concrete communicative behavior. Norton (1978) suggested that communication style is the habitual pattern developed by individuals and has a potentially major impact on correspondents' perceptual and affective responses [2]. One of the core elements of leadership is a leader's interpersonal communication style. Fleishman (1973) in a review of 20 years of research on the Ohio State leadership scale, offered the following as a definition for leadership: "interpersonal influence, directed through the communication process, toward the attainment of some goal or goals" [3]. Thus communication is an important part of leader behaviors and has significant effect on its followers.

From the view of information channel, communication can be divided into verbal and nonverbal communication (Burgoon J. K., et al. 1989) [4]. Contacts have two parts: contents portion and relevant portion. Contents portion show theme via language. So it can be seen that most contents and framework are expressed by verbal communication. In organization setting, as a direct and clear way, the communication between leaders and employees is achieved mainly by verbal exchange. For an organization, efficiency is a vital element. Direct verbal expression has advantage of accuracy information convey and comprehension, and quick information reception. Therefore, as an important part of leader's communication style, verbal communication style is essential to those who interested in the organizational setting since the process of communicating and filtering messages can be critical to the effective operation of the organization. What leaders say has a meaningful influence to the entire organization system. Furthermore, encouraging subordinates to communicate and participate in decision-making process can not only promote commitment from the subordinates, but also increase job satisfaction among people who interact and work interdependently. The magnitude of these relationships suggests that the construct of verbal communication style may be one of the important factors to be considered for organizational communication and leadership research and practice. From a practical perspective, these results suggest that the style of verbal communication is a potentially important determinant of employee reactions. In order to get the best out of their employees, leaders must be sure to use the proper verbal communication style which depends entirely on their target audience.

Leader's verbal communication style stems from communication theory and leadership theory. In respect of communication theory, communication styles have a different development. While the construct received significant attention before 1970s, efforts to generalize have been nominal. Once there was a generalized communication style construct for research pursuit, there was heightened emphasis laid on it for about two decades. And again since the last two decades there seems to be almost no research in this area (Chaganti \& Bikkina, 2011) [5], and less studied leader's verbal communication style. One of the reasons was an argument that communication competence can encompass communication style in observation. However, Chaganti and Bikkina hold a view that is a more proximate variable. Another is that small group research and leadership theory can be better metaphors to understand organizational behaviors and development. But one needs to understand that there is always scope to explain behaviors in terms of communicative acts. As to leadership theory, verbal communication style is mainly reflected in the leadership style. Though many researchers studied leadership styles, few extracted their verbal communication style to investigate. Several authors have noted that communication is central to leadership (Frese, Beimel \& Schoenborn, 2003; Kirkpatrick \& Locke 1996; Riggio, Riggio, Salinas \& Cole, 2003; Shamir, Arthur \& House, 1994) [6]-[9], but except for studies devoted to oratory skills and content in highly specific speech-like contexts, few have attempted to operationalize the verbal communication styles leaders use in their daily contacts with subordinates. Even fewer attempted to find out what the relations are of these verbal communication styles with outcome factors.

To sum up, although some authors have studied communication style, it was scattered in content and had several gaps in time. Moreover, they only studied the big concept and didn't discuss every component deeply. The goals of this paper are to operationalize a leader's verbal communication style and uncover the relations between leader's verbal communication style and employees' job satisfaction. On one hand, it refines and complements communication theory by introducing leader's verbal communication style. On the other hand, it applies communication theory to leadership area, chooses verbal communication style according to special research subject and environment and thus enriches leadership theory. At last, by studying relationship between leader's verbal communication and job satisfaction, it provides guide foundation for practice.

\section{Literature Review}

\subsection{Communication Style}

Chaganti and Bikkina (2011) think that communication style refers to a characteristic way of communicating [5]. 
It consists of an identifiable pattern of linguistic, vocal and nonverbal behaviors which are distinguishable from others' behavioral patterns. Thus it can be seen communication style refers to a characteristic way of communicating. It consists of an identifiable pattern of linguistic, vocal and nonverbal behaviors which are distinguishable from others' behavioral patterns.

Norton (1978) laid the foundation for the theory of communication. Norton defined communicator style as the way one verbally and paraverbally interacts to signal how literal meaning should be taken, interpreted, filtered, or understood. He conceptualized communicator style in terms of nine independent variables and one dependent variable. The independent variables (sub-constructs) are dominant, dramatic, contentious, animated, impression leaving, relaxed, attentive, open, and friendly. The dependent variable also a sub-construct is communicator image which represents an evaluative consequence of the first nine sub-constructs. Norton's view of communication style is fairly broad and holistic. His Communicator Style Measure (CSM) has generated the most research within the communication discipline and CSM is a self-report measure [2]. Ganster, Petelle, Baker, Dallinger and Backus (1981) empirically examined Norton's communication style scale and noted a number of psychometric deficiencies. They argued that these problems are symptomatic of a lack of theoretical development. In an attempt to overcome these problems, they gave leaders' self-report results and employees' perceived results and employed a semantic differential measurement model and included factors such as dramatization, dominance, nonverbal expressiveness, amount of exaggeration, and emotionality [10].

For use within an organizational setting, Richmond and McCroskey (1979) specifically designed the Management Communication Style Scale (MCS) [11]. It measures employee satisfaction on a continuum of leadership orientations ranging from the extreme "boss centered" to "subordinate centered". The MCS examines four dimensions of the superior-subordinate interface: tell, sell, consult, and join. Though there is a categorization within MCS, these are only broad variables. Several authors have attempted to integrated diverse communication style scales with the interpersonal model, which consists of the following two main interpersonal (communicative) dimensions: friendliness/affiliation and dominance (Sorenson \& Savage, 1989) [12]. With regard to leader's communication style, DeVries, Bakker-Pieper and Oostenveld (2010) defined a leader's communication style as a distinctive set of interpersonal communicative behaviors geared toward the optimization of hierarchical relationships in order to reach certain group or individual goals [13].

The question is: are the findings of the communication style literature replicable in the leadership context? The leadership style literature may be characterized by referring to two main phases: approximately 35 years of studying leader consideration and initiating structure from 1953 until the middle of the 1980s and approximately 30 years of studying charismatic-transformational leadership from the middle of the 1980s until the present. Studies on leader's communication have kept up with this shift in focus. In a review of the relations between interpersonal communication behaviors and leadership, there are strong relationship among communication style and leadership style. Chaganti and Bikkina (2011) studied leadership theory from a communication style perspective. Their study critically analysed the Stogdill's Leader Behavior Description Questionnaire from the view point of Norton's theory of Communication Style [5]. MCS of a supervisor within an organization is a function of both the management style imposed on the supervisor by the organization (or chosen by the supervisor within the parameters permitted by the organization) and the communication style of the individual supervisor which that individual brings to the organizational context (Richmond, McCroskey \& McCroskey, 2001) [14]. Bradley and Baird's (1977) investigation associated several approaches to management with varying dimensions of communication style [15]. Results indicated that democratic management was characterized by relaxation, animation, attentiveness, and friendliness in communication style, laissez-faire leadership was similar, except for a lack of animation, and autocratic managers were characterized primarily by dominant communication behavior. DeVries, Bakker-Pieper and Oostenveld (2010) also found that there are several strong correlations between the communication styles of a leader and his/her leadership style [13]. The magnitude of these relationships suggests that the construct of communication style may be an important variable for leadership research and practice. The research of leadership style is inseparable from leadership communication style. Concerning the role of communicator style in leadership settings is meaningful.

Leader's communication style restricts subject to leader. Leader's communication behavior is an important part of leader's behaviors and their communication style is embodied in leadership style. According to the result of literature review, it can be seen that most researches is about general individual communication style. A number of researchers talked about leader's communication style and few studied leader's verbal communication style. Even though some investigated the relationship between leader's communication style and leadership 
style, only De Vries and his partners are engaged in a long time study. As described in the introduction, leader's verbal communication style has its special uniqueness and special significance, which leads to the variable selected to study. Based on Norton's communication style theory; referring to the integration result of different researches (Sorenson and Savage 1989), that is communication style have two dimension: friendliness/affiliation and dominance; combing Richmond and McCroskey's study about managers' communication style under organization environment; considering the particularity of leaders, we discuss leader's verbal communication style from the view of autocratic and supportive.

Leader's verbal communication style refers to the characteristic way a leader sends verbal and paraverbal signals in order to reach certain organizational or individual goals. Autocratic verbal communication style means the tendency to display a "take-charge" attitude via verbal communication style. They give advice freely and frequently initiate demands; more assertive, argumentative and tend to seek control over others; enjoy absolute authority and voice; rarely accept comments and suggestions Supportive verbal communication style means the tendency to seek and enjoy social relationships via verbal communication style. Supportive verbal communication style means creating a friendly and supportive work environment. It displayed by expressing feelings freely, open, friendly and taking care of others. They like personal associations. The person who is low in sociability is more reserved and formal in social.

\subsection{Leader's Verbal Communication Style and Job Satisfaction}

Job satisfaction has received significant attention in studies of the work place. Firstly, this is due to the general recognition that job satisfaction can be the major determinants of organizational performance. Job satisfaction is of major concern when outcome variables such as absenteeism or organizational inefficiency such as counterproductive behavior or sabotage, are dealt with because job satisfaction is supposed to be a major cause of such problems (Dormann, \& Zapf, 2001) [16]. Secondly, job satisfaction is relevant for all those who are interested in the subjective evaluation of working conditions such as responsibility, task variety, or communication requirements because job satisfaction is supposed to be strongly caused by such conditions. Social psychologists believe that attitude is the cornerstone of understanding human behaviors. Attitude significantly or substantially predicts human behavior. Via research on job satisfaction, employee positive organizational behavior and negative organizational behavior can be better predicted. Thus we can increase organizational performance by improving job satisfaction.

Cranny, Smith, and Stone (1992) suggested that there is a clear consensus in the definition of job satisfaction [17]. Their "consensus" definition is that job satisfaction is "an affective (i.e., emotional) reaction to one's job, resulting from the incumbent's comparison of actual outcomes with those that are desired (expected, deserved, and so on)". This definition is essentially equivalent to the definition offered by Locke (1976), who said that job satisfaction is a "pleasurable or positive emotional state resulted from an appraisal of one's job or job experiences". He concluded that the typical job dimensions that had been studied by previous investigations mixes two different levels of analysis, namely Events or Conditions (work, pay, promotion, recognition, benefits, working conditions) and Agents (supervision, co-workers, and company and management) [18]. A definition of job satisfaction as the attitude one holds about one's jobs is also prevalent. So, for example, Miner (1992) states that "it seems desirable... to treat job satisfaction as generally equivalent to job attitudes" [19] and, more recently, Brief (1998) says that job satisfaction "is an attitude toward one's job" [20]. Weiss (2002) argue that defined as an attitude, job satisfaction is "a positive (or negative) evaluative judgment one makes about one's job or job situation" [21].

Numerous antecedents of job satisfaction have been suggested in the earlier studies. Hoppock (1935) published the first intensive study of job satisfaction. His results and interpretations emphasized the multiplicity of factors that could affect job satisfaction, including fatigue, monotony, working conditions, supervision and achievement [22]. Churchill, Ford, and Walker (1974) articulated seven sources of salesperson satisfaction(or dissatisfaction): the work itself, colleagues, supervisors, company policy, remuneration, opportunities for promotion, and customers, all of which have the potential to contribute to overall job satisfaction [23]. Arnold and Feldman (1986) supposed six principal sets of variables influence employees' positive or negative attitudes toward their jobs: salary, the job itself, promotion opportunities, management style, the work group, and working conditions [24]. Brief (1998) postulated that the antecedents of job satisfaction fall into two broad categories: situational antecedents (e.g., job circumstances) and dispositional antecedents (e.g., personality) [20]. Leader- 
ship (Williams and Hazer, 1986) and organizational culture (Trice and Beyer, 1993) were shown to have significant impact on both job satisfaction [25] [26].

From the previous review, it can be known that job satisfaction is an attitude and its influential factors can come from superiors, management style, etc., and these are all correlated with leader's verbal communication style. A number of variables operating within organizational setting have found to impact job satisfaction. Many of these have, at most, a tangential relationship to communication among employees or between superiors and subordinates. Although it is clear that leader's verbal communication style is not the only, and possibly are not even the most important determinates of job satisfaction, research has indicated that communication style do predict meaningful variance in job satisfaction across different organizations. The present research effort was designed to replenish and extend some previous studies that have sought to link communication variables with job satisfaction. Specifically, the research mainly examined the direct and indirect relationship between leader's verbal communication style and job satisfaction.

The literature on communication styles and outcomes implies that communication styles are meaningfully related to job satisfaction. Richmond, McCroskey, Davis, and Koontz (1980) examined supervisor's communication of each type of power for relationships with employee satisfaction [27]. Managers who exercise more employee centered and interactive management communication style would increase satisfaction among employees and vice versa. Results of doctor-patient studies suggest that especially a supportive (i.e., friendly and caring) communication style is associated with higher satisfaction among patients (Schmid Mast, Hall \& Roter, 2007) [28]. While a dominant style is associated with less satisfaction among patients and less favorable outcomes. While numerous study show that the subordinate's and superior's satisfaction with their relationship will be affected by leader's communication style, Barlow, Hansen, Fuhriman, and Finley (1982) found that leader's verbal styles had no effect on satisfaction with leaders [29]. Hampton, Dubinsky, and Skinner (1986) also found no relationship between leadership behavior and job satisfaction. Based on this discussion, the following hypotheses are advanced [30].

Hypothesis 1a. Autocratic verbal communication style will be negatively related to job satisfaction. Leaders who exercise more autocratic verbal communication style will decrease satisfaction among employees.

Hypothesis 1b. Supportive verbal communication style will be positively related to job satisfaction. Leaders who exercise more supportive verbal communication style will increase satisfaction among employees.

\subsection{Leaders' Verbal Communication Style and Work Engagement and Job Burnout}

Work engagement. Kahn’s (1990) conceptualization of engagement refers to a psychological connection with the performance of work tasks rather than an attitude toward features of the organization or the job (Maslach, Schaufeli \& Leiter, 2001) [31] [32]. He proposed that personal engagement represents a state in which employees "bring in" their personal selves during work role performances, investing personal energy and experiencing an emotional connection with their work. In this view, work roles represent opportunities for individuals to apply themselves behaviorally, energetically, and expressively, in a holistic and simultaneous fashion (Kahn, 1992; Rich, Lepine \& Crawford, 2010) [33] [34]. As such, work engagement is fundamentally a motivational concept that represents the active allocation of personal resources toward the tasks associated with a work role. Bakker, Schaufeli, Leiter, and Taris (2008) introduce the emerging concept of work engagement: a positive, fulfilling, affective-motivational state of work-related well-being that is characterized by vigor, dedication, and absorption [35]. The study refers Bakker, Schaufeli, Leiter, and Taris's opinion about work engagement. Work engagement is a relatively long-lasting, work-related psychological state, which has characteristics of positive, fulfilling and affective. It can be divided into three dimensions: vigor, dedication and absorption. Vigor refers to high levels of energy and resilience, the willingness to invest effort in one's job, not being easily fatigued, and persistence in the face of difficulties. Dedication refers to a strong involvement in one's work, accompanied by feelings of enthusiasm and significance, and by a sense of pride and inspiration. Absorption refers to a pleasant state of total immersion in one's work which is characterized by time passing quickly and being unable to detaching oneself from the job.

Maslach (1993) defines burnout as a psychological syndrome of emotional exhaustion, depersonalization, and reduced personal accomplishment that can occur among individuals who work with other people in some capacity' (our italics) [36]. Emotional exhaustion refers to feelings of being emotionally overextended and depleted of one's emotional resources. Depersonalization involves a negative, indifferent, or overly detached attitude to others (often the recipients of one's services or care). Finally, reduced personal accomplishment refers to a de- 
cline of feelings of competence and successful achievement in one's work. According to this conceptualzation, Maslach, and Jackson (1986) devise three-scale Maslach Burnout Inventory (MBI) that measures burnout among human services professionals (the MBI HSS, for "Human Services Survey”) [37]. In order to overcome context limitation, Maslach (1996) developed the MBI-GS (for General Survey), which consists of three scales, tapping emotional exhaustion, cynicism, and reduced professional efficacy. The study refers to the view of Maslach (1996). Burnout is a state of exhaustion in which one is cynical about the value of one's occupation and doubtful of one's capacity to perform [38]. The exhaustion items refer to fatigue, but without referring to people as the source of those feelings. Cynicism reflects indifference or a distant attitude towards work. Finally, reduced professional efficacy has a broader scope than personal accomplishment as measured by the MBI-HSS; item compasses both social and non-social accomplishments at work.

Work engagement and job burnout. According to Maslach and Leiter (1997), engagement is characterized by energy, involvement and efficacy-the direct opposites of the three burnout dimensions [39]. Schaufeli and his colleagues (2007) took a different approach to prove it Vigor and dedication are considered direct opposites of the core burnout dimensions of exhaustion and cynicism, respectively [40]. More recently, Halbesleben (2010) summarized that with a few exceptions, that work engagement constructs were negatively associated with burnout [41].

Communication is the vehicle for dissemination of information, instructions, and (possibly most important) affect. Communication style variables are habitual patterns developed by individuals and have a potentially major impact on interactants’ perceptual and affective responses (Norton, 1978) [2]. From the previous review, it can be concluded that work engagement and job burnout are affective-motivational variables. Thus, communication style may affect work engagement in some ways. On the other hand, the relationship between leadership and performance also has received considerable scholarly attention. Leadership theory argues that individuals implicitly believe that certain outcomes follow from leadership behavior. Leaders are critical elements of the work context that can influence how individuals view their work. In line with the arguments presented by Kahn (1990), Yousef (2000) found that the leadership behavior is related with the work outcomes of job performance [42]. From the previous review of communication style, it is can be seen that there are close relationship between communication style and leadership. Hence it is reasonable to predict there are significant relationship between leader's verbal communication style and work engagement and job burnout.

Given the limited research on employee work engagement/job burnout and leader's communication style, there has been little in the way of model or theory development about the relationship between leader's verbal communication style and work engagement/job burnout. We can get prediction from related researches.

Simpson's (2009) finding suggests that organizational factors versus individual contributors significantly impact engagement at work [43]. As an important component of organizational factors, leader's verbal communication style may have effect on work engagement/job burnout.

Refer to path-goal theory, supportive leader behavior provides psychological support for subordinates. Such behavior is especially needed under conditions in which tasks or relationships are psychologically or physically distressing. Supportive relationships increase the quality of relationships between superiors and subordinates and decreases subordinate stress. Supportive leader behavior will lead to increased subordinate effort and satisfaction by enhancing leader subordinate relationships and self-confidence, lowering stress and anxiety, and compensating for unpleasant aspects of the work (House, 1996) [44]. Work engagement/job burnout mainly shows a sort of a state of mind and emotional reaction together with stress, self-confidence, moods and so on. So it is reasonable to relate supportive verbal communication style with work engagement/job satisfaction.

Autocratic communication style was often related to some bad results, such as malpractice claims (Ambady et al. 2002) and less intrinsic motivation (Noels et al. 1999) [45] [46]. Three models built by Laschinger and Finegan (2005) suggest that empowerment as effects on burnout/work engagement through various areas of work life [47]. The existing research also found that powerless workers consumed greater quantity of alcohol, and of higher frequency absenteeism (Seeman \& Anderson, 1983) [48]. On the contrary, empowered employees demonstrated a 40\% drop of absenteeism (Bennett, 1998) [49]. Cathcart et al.'s (2004) study results suggest nurses' employee engagement is higher when unit managers' span of control is lower [50]. Under autocratic verbal communication style, employees or subordinates have no say in the decision making process and has to completely obey the decisions of the leader without question. Leaders who use the autocratic style have to be mindful of their intensity. This is because such employees might tend to become more closed up and unwilling to provide suggestions for the betterment of the organization. Employees who cannot stand the pressure leave 
eventually; leading to high turnover and talent loss for the company.

Based on this discussion, the following hypotheses are advanced.

Hypothesis 2a. Leader's autocratic verbal communication style will be negatively related to work engagement.

Hypothesis 2b. Leader's supportive verbal communication style will be positively related to work engagement.

Hypothesis 2c. Leader's autocratic verbal communication style will be positively related to job burnout.

Hypothesis 2d. Leader's supportive verbal communication style will be negatively related to job burnout.

\subsection{Work Engagement, Job Burnout and Job Satisfaction}

Job satisfaction and engagement have fundamental differences, in that engagement connotes activation, as opposed to satisfaction, which is more similar to satiation (Macey \& Schneider, 2008) [51]. Further, Job satisfaction is an evaluative description of job conditions or characteristics (e.g., "I like my pay"), which is a feature of a job attitude (Brief \& Weiss, 2002) [52], whereas work engagement is a description of an individual's experiences resulting from the work (e.g., "I feel vigorous when working”). In this study, we propose a test of our framework, specifies work engagement/job burnout as a mediating link between leader's verbal communication style and job satisfaction.

Although the relationships among potential antecedents and consequences of work engagement/job burnout have not been rigorously conceptualized, much less studied, the existing research can also provide some guidance. The experience of engagement has been described as a fulfilling, positive work-related experience and state of mind and has been found to be related to good health and positive work affect (Sonnentag, 2003) [53]. Saks (2006) study antecedents and consequences of employee engagement. The result show that job engagement predicted job satisfaction significantly [54]. Schaufeli, Taris, and Van Rhenen (2008) empirically proved that engagement was positively related to job satisfaction, whereas job burnout was negatively related to job satisfaction. The existing research show the significance relationship between work engagement, job burnout and job satisfaction, but who decides who is controversial [55]. For example, a study examined by Visser, Smets, Oort, and De Haes (2003) showed that burnout was explained by low satisfaction [56]. When satisfaction was low, the risk for emotional exhaustion — the central aspect of burnout—increased considerably. The following hypotheses are proposed based on this discussion.

Hypothesis 3a. Job satisfaction will be positively related to work engagement. More work engagement will bring about higher job satisfaction.

Hypothesis $3 \mathrm{~b}$. Job satisfaction will be negatively related to job burnout. More job burnout will bring about lower job satisfaction.

Taken as a whole, the hypotheses developed so far imply a mediated model. Leader's verbal communication style has direct impact on job satisfaction (cf. 2.2), work engagement and job burnout (cf. 2.3). Work engagement and job burnout affect their job satisfaction (cf. 2.4). The model suggests that leader's verbal communication style is ultimately related to job satisfaction, but that these linkages are mediated through work engagement/ job burnout. Saks (2006) found that job and organization engagement mediated the relationships between the antecedents and job satisfaction, organizational commitment, intentions to quit, and organizational citizenship behavior [54]. The following hypotheses are advanced based on this discussion.

Hypothesis 4a. Work engagement mediates the negative relation between autocratic verbal communication style and job satisfaction.

Hypothesis $4 \mathrm{~b}$. Job burnout mediated the negative relation between autocratic verbal communication style and job satisfaction.

Hypothesis 4c. Work engagement mediates the positive relation between supportive verbal communication style and job satisfaction.

Hypothesis 4d. Job burnout mediates the negative relation between supportive verbal communication style and job satisfaction.

\section{Method}

\subsection{Participants and Procedure}

Subjects in this research were primarily MBA students in Dalian University of Technology. Survey packets 
were sent directly from the researchers to 400 management employees. Managers were asked to participate, and their anonymity was assured. By this way we hoped to reduce participants' evaluation apprehension that might potentially contaminate the truthfulness of their response (Podsakoff, MacKenzie \& Podsakoff, 2012) [57]. 264 (66\%) were elected to do so. Those participating were asked to complete a survey and to select one subordinate to respond as well. The manager then provided an employee survey packet and return it directly to the researchers. Again, anonymity was assured, but a coding system on the survey was used to associate employees with their supervisors. A total of 237 employee surveys were returned. Thus, the sample consisted of 237 dyads. The dyad tradition represents a contrast to the group tradition, where the supervisor is understood to use the same (and presumably "best") style with all subordinates. Under the method, it becomes reasonable to expect that supervisors could use different communication style with different subordinates. At the same time, we can avoid the errors of homologous to some extent.

These 237 employees engaged in various industries, including manufacturing, construction, finance, media, and services. As presented in Table 1, 47 percent of the participants were female, and 53\% were male. Moreover, $35.2 \%$ of participants were younger than $31 \%$, $57.2 \%$ were between $31 \%$ and $40 \%$, and $7.6 \%$ were older than 40 . Approximately $53.4 \%$ of the participants had master's degree, and $43.6 \%$ had bachelor's degree, and only $3 \%$ had received below high school education. As to type of employment, $37.9 \%$ correspondents worked in state-owned enterprises, $31.8 \%$ in the foreign capital enterprises, $29.2 \%$ in the private enterprises, and the rest were employed in the governments. Of the participants, $40.7 \%$ were general staff, $19.5 \%$ were first-line managers, $32.6 \%$ middle managers, and $7.2 \%$ senior managers. With respect to the level of income, $19.5 \%$ of the participants earned income under 4001 RMB monthly, 26.7\% earned salary between 4001 RMB and 6000 RMB, and 19\% earned salary between 6001 RMB and 8000 RMB, and finally, 33.9\% had more than 8000 RMB of income per month. As noted above, the samples employed were highly diverse which are extremely important to the interpretation of the results of this investigation.

Table 1. The socio-demographic characteristics.

\begin{tabular}{|c|c|c|c|}
\hline & Sample distribution & Sample size & Percentage (\%) \\
\hline \multirow[t]{2}{*}{ Gender } & Male & 126 & 53.0 \\
\hline & Female & 111 & 47.0 \\
\hline \multirow[t]{3}{*}{ Age } & Younger than 31 & 83 & 35.2 \\
\hline & Between 31 and 40 & 136 & 57.2 \\
\hline & Older than 40 & 18 & 7.6 \\
\hline \multirow[t]{3}{*}{ Education } & Bachelor & 103 & 43.6 \\
\hline & Master & 127 & 53.4 \\
\hline & Others & 7 & 3.0 \\
\hline \multirow[t]{4}{*}{ Salary (RMB) } & Under 4001 & 47 & 19.5 \\
\hline & Between 4001 and 6000 & 64 & 26.7 \\
\hline & Between 6001 and 8000 & 45 & 19.0 \\
\hline & More than 8000 & 81 & 33.9 \\
\hline \multirow[t]{4}{*}{ Position } & General Staff & 97 & 40.7 \\
\hline & First-line Managers & 46 & 19.5 \\
\hline & Middle Managers & 77 & 32.6 \\
\hline & Senior Managers & 17 & 7.2 \\
\hline \multirow[t]{4}{*}{ Business nature } & State-owned Enterprises & 90 & 37.9 \\
\hline & Foreign Capital Enterprises & 75 & 31.8 \\
\hline & Private Enterprises & 69 & 29.2 \\
\hline & Government Departments & 3 & 1.1 \\
\hline
\end{tabular}




\subsection{Measurement}

Leaders' verbal communication style. Norton's CSM (Communicator style measure) is specific, refined and broad. The verbal communication style of leader was measured with items from Norton's (1978) CSM. Refer to research on the integration of communication style and the distinctive role of leaders in organization context, four dimensions in CSM were employed: dominant, contentious, open and friendly. In line with the concept definition ahead, dominance and contentious amalgamated into one dimension called dominance; open and friendly amalgamated into one dimension called sociality. Why we call this have two theory bases. The first theoretical basis was Lewin's (1959) definition of autocratic leadership style [58]. Authoritarian leaders clutch the reins of power and enjoy absolute authority and voice; focus on team goals and emphasize efficiency and do not care about the needs of the members; limit subordinates participation and rarely accept comments and suggestions; tend to judge the work based on individual opinions; team members will be strictly monitored. Secondly, according to path-goal theory, supportive leader behavior is behavior directed toward the satisfaction of subordinates needs and preferences, such as displaying concern for subordinates' welfare and creating a friendly and psychologically supportive work environment. It is characterized by caring, friendly, open, enthusiastic and so on. Aimed at suggests proposed by Ganster, Petelle, Baker, Dallinger, and Backus (1981), the 20-item scale were amended slightly. Because the Norton measure assesses one's self-perception of communicator style, the stems of the items were rewritten so they would assess a subordinate' perception of his or her leader's style. At last, the leader's self-report result and employees' perceived result were both investigated. After the pre-test, the item A2, A6, A9, A12, A13, A16, A17, A19 were removed due to their lower standard factor loading coefficient $(<0.5)$. The final measure contains 12 items with the reliability of 0.841 (Cronbach's Alpha), and validity of 0.862 (KMO, $\mathrm{p}<0.001$ ). A confirmatory factor analysis (CFA) was conducted with the result of supporting the two-factor model $\left(\chi^{2}=530.98, \mathrm{df}=158\right.$, comparative fit index $[\mathrm{CFI}]=0.77$, root mean square error of approximation $[$ RMSEA] $=0.156$ ). Thus, the first seven components were used to create one type of leaders' verbal communication styles-dominant verbal communication style and the last five components used to create the second verbal communication style-social verbal communication style. Sampling item of the leader scale was "I have a tendency to dominate informal conversations with other people." Example item of employee scale was "I think my leader's verbal communication style tend to be: he is very argumentative". The measured uses a 5point Likert-type scale ( 1 = strongly disagree to 5 = strongly agree).

Job satisfaction. Job Satisfaction Survey (JSS) developed by Spector (1985) was adopted, which measures the following nine aspects of job satisfaction: satisfaction with pay, promotional opportunities, fringe benefits, contingent rewards (appreciation and recognition), supervision, co-workers, nature of work itself, communication, and work conditions. Spector's questionnaire involves nine dimensions of 36 items [59]. In this study, we selected the five dimensions which exhibit a closer relationship with research topics and were more consistent with the Chinese organizational cultures. The five dimensions are satisfaction with pay, promotional opportunities, supervision, communication and nature of work. The higher the score is, the more the participants will feel satisfied. The pre-test result shows that the measure's reliability is 0.933 (Cronbach's Alpha), and validity is $0.892(\mathrm{KMO}, \mathrm{p}<0.001)$. The measured uses a 5 -point Likert-type scale $(1=$ strongly disagree to $5=$ strongly agree).

Work engagement. UWES (Utrecht Work Engagement Scale) developed by Schaufeli, Salanova, GonzálezRomá, and Bakker (2002) as selected to measure work engagement [60]. The Chinese version translated by Zhang and Gan (2005) was used in the survey. The reliability and validity has been tested in Chinese context (Zhang and Gan, 2005) [61]. The confirmatory factor analysis result was consistent with the hypothesized three-factor model of work engagement consisting of Vigor, Dedication and Absorption. All the three sub-scales showed acceptable internal consistencies. The results have showed UWES is reliable and valid for application in China. The pre-test results also showed that most items have a good standard factor loading coefficient except item C10 with $0.38(<0.5)$, which was deleted at last. Sample items were phrased as "When I get up in the morning, I feel like going to work" and "When I am working, I forget everything else around me". We used the 16-item-measure which results in a reliability coefficient (Cronbach's alpha) of 0.966, and validity coefficient (Kaiser-Meyer-Olkin) of $0.900(\mathrm{p}<0.001)$. The measured uses a 5-point Likert-type scale $(1=$ strongly disagree to 5 = strongly agree).

Job burnout. MBI-GS (Maslach, 1996) was used to measure job burnout, which allows burnout to be studied independently from its specific job context. It consists of 16 items representing emotional exhaustion (five items, 
e.g. "working all day is really a strain for me”); cynicism (five Items, e.g. "I doubt the significance of my work”), and reduced professional efficacy (six items, e g. "I have accomplished many worthwhile things from this job"). The scale ranged from 1 - 5 where 1 represents "never", 2 represents "a few times a year", 3 represents "sometimes (a few times a month)", 4 represents "often (a few times a week)", and 5 represents "always" [38]. Statistical tests showed that all of the factor loading coefficients were higher than 0.5 except D10 $(0.01<0.5)$. The final 15-items-measure was used in the study ending up with a reliability coefficient (Cronbach's alpha) of 0.798, and validity coefficient (Kaiser-Meyer-Olkin) of.868 ( $<<0.001)$.

Control variables. All those participants' social-demographic variables such as gender, age, education, and monthly income, job position, and nature of the company are included and treated as control variables.

\subsection{Statistical Analysis}

\subsubsection{Statistical Descriptive Analysis}

Correlations between variables are presented in Table 2. It can be seen that the autoratic verbal communication style was negatively related to job satisfaction $(\mathrm{r}=-0.393, \mathrm{p}<0.01)$ and work engagement $(\mathrm{r}=-0.152, \mathrm{p}<$ $0.05)$, and positively related to job burnout $(\mathrm{r}=0.250, \mathrm{p}<0.001)$. Supportive verbal communication style had a positive relation with job satisfaction $(r=0.165, \mathrm{p}<0.05)$. On the other hand, job satisfaction had positive relationship with work engagement $(\mathrm{r}=0.698, \mathrm{p}<0.01)$ and it had a negative relationship with job burnout $(\mathrm{r}=$ $0.620, \mathrm{p}<0.01$ ).

As far as the effect of control variables on dependent variables is concerned, the results of analysis of variance (ANOVA) indicated that only monthly income had significant effects on job satisfaction $(\mathrm{p}=0.007)$. The rest have no significant effect on job satisfaction $(\mathrm{p}>0.05)$.

Table 2. Correlations of the variables in the sample.

\begin{tabular}{|c|c|c|c|c|c|c|}
\hline & & $\mathrm{AD}$ & AS & JS & WE & JB \\
\hline \multirow{3}{*}{$\mathrm{AD}$} & $\begin{array}{c}\text { Pearson correlation } \\
\text { coefficient }\end{array}$ & 1 & $0.362^{* *}$ & $-0.393^{* *}$ & $-0.152^{*}$ & $0.250^{* *}$ \\
\hline & Sig. (Bilateral) & & 0.000 & 0.000 & 0.019 & 0.000 \\
\hline & $\mathrm{N}$ & 237 & 237 & 237 & 237 & 237 \\
\hline \multirow{3}{*}{ AS } & $\begin{array}{c}\text { Pearson correlation } \\
\text { coefficient }\end{array}$ & $0.362^{* *}$ & 1 & 0.126 & $0.165^{*}$ & 0.011 \\
\hline & Sig. (Bilateral) & 0.000 & & 0.053 & 0.011 & 0.869 \\
\hline & $\mathrm{N}$ & 237 & 237 & 237 & 237 & 237 \\
\hline \multirow{3}{*}{ JS } & $\begin{array}{c}\text { Pearson correlation } \\
\text { coefficient }\end{array}$ & $-0.393^{* *}$ & 0.126 & 1 & $0.698^{* *}$ & $-0.620^{* *}$ \\
\hline & Sig. (Bilateral) & 0.000 & 0.053 & & 0.000 & 0.000 \\
\hline & $\mathrm{N}$ & 237 & 237 & 237 & 237 & 237 \\
\hline \multirow{3}{*}{ WE } & $\begin{array}{c}\text { Pearson correlation } \\
\text { coefficient }\end{array}$ & $-0.152^{*}$ & $0.165^{*}$ & $0.698^{* *}$ & 1 & $-0.625^{* *}$ \\
\hline & Sig. (Bilateral) & 0.019 & 0.011 & 0.000 & & 0.000 \\
\hline & $\mathrm{N}$ & 237 & 237 & 237 & 237 & 237 \\
\hline \multirow{3}{*}{ JB } & $\begin{array}{c}\text { Pearson correlation } \\
\text { coefficient }\end{array}$ & $0.250^{* *}$ & 0.011 & $-0.620^{* *}$ & $-0.625^{* *}$ & 1 \\
\hline & Sig. (Bilateral) & 0.000 & 0.869 & 0.000 & 0.000 & \\
\hline & $\mathrm{N}$ & 237 & 237 & 237 & 237 & 237 \\
\hline
\end{tabular}

Note. $\mathrm{AD}=$ autocratic verbal communication style, $\mathrm{AS}=$ supportive verbal communication style, $\mathrm{JS}=$ job satisfaction, $\mathrm{WE}=$ work engagement, JB = job burnout. 


\subsubsection{Harman's Single Factor Test}

Considering the significant correlation between the variables, we firstly need to test if a homologous bias existed between the various measurement indicators. We used Harman's single factor test method test method whose basic assumption is that if a large number of homologous biases exist, when performing the factor analysis, the results will precipitate a single factor or a common factor explains most of the variation in the variables. According to this method, we conducted exploratory factor analysis to all indicators in order to examine the degree of homology bias. In the unrotated factor analysis results, the first factor's unrotated explained variance was only $31.202 \%$, which showed that there was only a slight homology bias between the measurement indicators. It might be derived from the close distribution of the similar questions and social desirability issues, and it was not enough to damage the overall quality of the sample data. So the analysis can be continued.

\subsubsection{Hypotheses Testing}

In testing Hypotheses 1a and 1b, we simultaneously entered the two dimensions of leader's verbal communication style and job satisfaction in the SEM (structural equation model). The results are presented in Figure 1.

It can be seen that there was negative relationships between the autocratic verbal communication style and job satisfaction $(\beta=-0.55, \mathrm{p}<0.001)$. And there are statistically positive relationship between the supportive verbal communication style and job satisfaction $(\beta=0.50, \mathrm{p}<0.001)$. The results provide general support for hypothesis $1 \mathrm{a}, 1 \mathrm{~b}$.

To test other hypotheses that work engagement/job burnout mediates all the relationships between leader verbal communication style and job satisfaction, we adopted suggestions proposed by Baron \& Kenny (1986) and Judd \& Kenny (1981a) [62] [63]. This procedure involves three criteria for determination of mediation:

1) There must be a significant relationship between the independent variable and the dependent variable,

2) There must be a significant relationship between the independent variable and the mediating variable, and

3) The mediator must be a significant predictor of the outcome variable in an equation including both the mediator and the independent variable.

The first criteria were test in Figure 1 and results showed that there were significant relationships between leader's verbal communication style and job satisfaction. In order to test the mediation effects of work engagement/job burnout, leader's verbal communication style, work engagement/job burnout, job satisfaction were simultaneously entered in the structural equation model (SEM).

First, leader's verbal communication style, work engagement and job satisfaction were simultaneously entered in the SEM. It was found that the full model including total and indirect linkages from the two leader verbal communication style dimensions to job satisfaction fit the data very well, $\chi^{2}(1074)=3105.78$, CFI $=0.94$, RMSEA $=0.090$. The results were shown in Figure 2.

In Figure 2, the path coefficients from autocratic verbal communication style and social supportive verbal communication style to work engagement were both significant $(\beta=-0.28, \mathrm{p}<0.001 ; \beta=0.27, \mathrm{p}<0.001$, respectively), which support hypothesis $2 \mathrm{a}$ and $2 \mathrm{~b}$ and provided the basis for testing the second criterion at the same time. Work engagement significantly predicts job satisfaction $(\beta=0.67, \mathrm{p}<0.001)$, which supports hypothesis $3 \mathrm{a}$ and meets the third criteria. So it is clear that work engagement mediates the relationship between

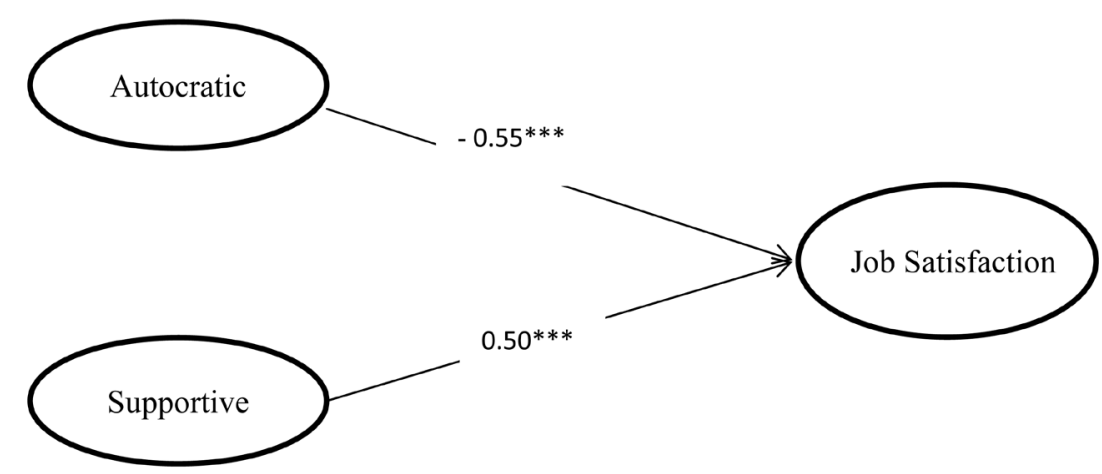

Figure 1. Structural equation model results of verbal communication style and job satisfaction. Note: All coefficients are standardized coefficients. ${ }^{*} \mathrm{p}<0.05{ }^{* *} \mathrm{p}<0.01$; $\mathrm{p}<0.001$. 
leader's verbal communication style and job satisfaction. Thus, hypothesis 4a and 4c were supported.

In the same way, leader's verbal communication style, job burnout and job satisfaction were simultaneously entered in the SEM. The full model also fits the data very well, $\chi^{2}(983)=5296.44$, CFI $=0.81$, RMSEA $=0.136$. The results were shown in Figure 3.

In Figure 3, the path coefficients from autocratic verbal communication style to job burnout were significant $(\beta=0.32, \mathrm{p}<0.001$ ), while the pate coefficient from supportive verbal communication style to job burnout were not significant. Thus, hypothesis $2 \mathrm{c}$ was supported and $2 \mathrm{~d}$ was refused. Job burnout significantly predicts job satisfaction $(\beta=-0.62, \mathrm{p}<0.001)$ and supports hypothesis $3 \mathrm{~b}$. It can be seen that, hypothesis $4 \mathrm{~b}$ was supported and hypothesis $4 \mathrm{~d}$ was refused.

In a nutshell, although the SEM results supported the mediating effects of work engagement between leader's verbal communication style and job satisfaction, job burnout only mediates the relationship between leader's autocratic verbal communication style and job satisfaction and the mediating effect the between leader's social supportive verbal communication style and job satisfaction was non-existent. Meanwhile, all mediating effect was partial mediation as the total path coefficient was not equal to the indirect path efficient.

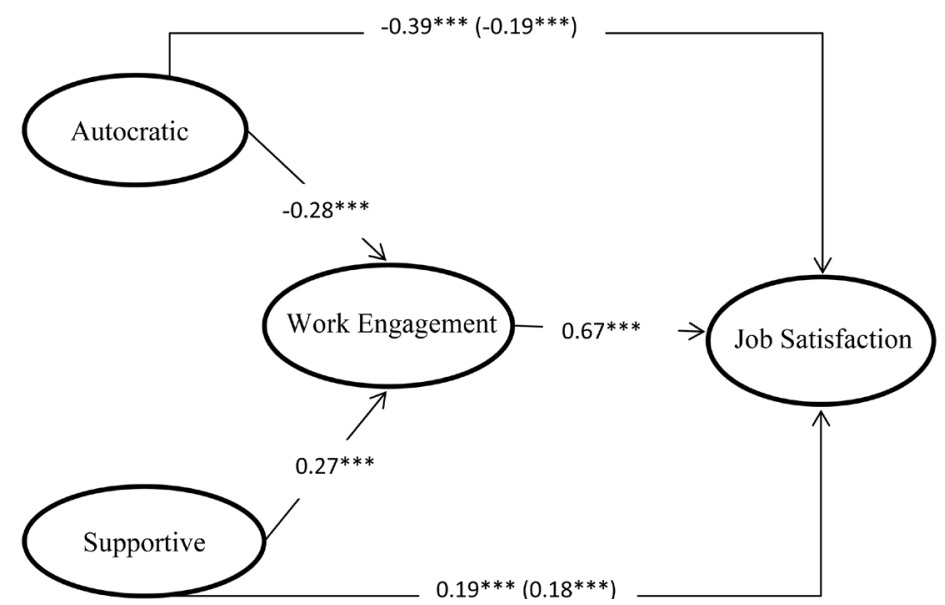

Figure 2. The mediating model of work engagement. Note: All coefficients are standardized coefficients. Values outside parentheses represent direct effects; values in parentheses represent indirect effects. ${ }^{*} \mathrm{p}<0.05$; ${ }^{* * *}<0.01 ;{ }^{* * *} \mathrm{p}<0.001$.

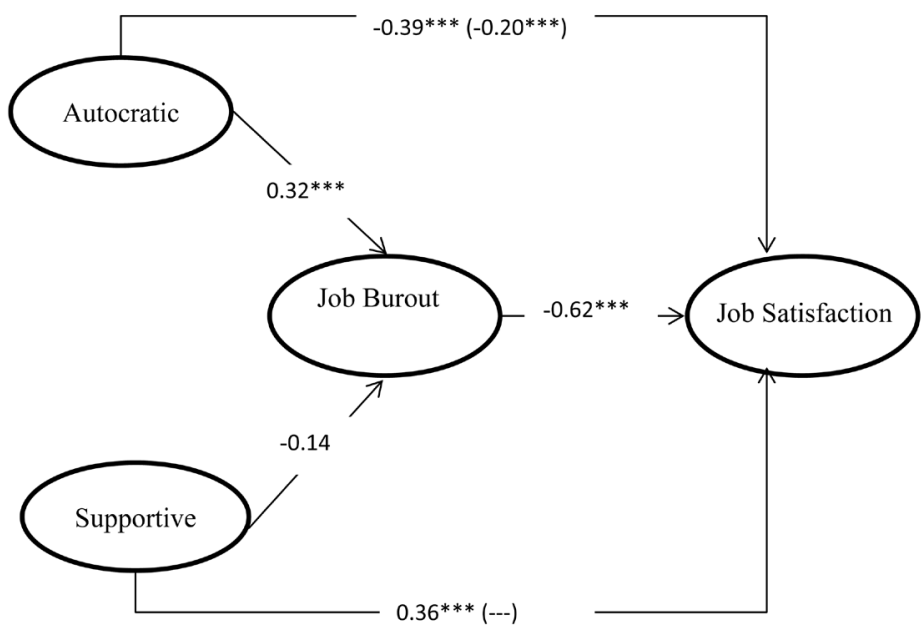

Figure 3. The mediating model of job burnout. Note: All coefficients are standardized coefficients. Values outside parentheses represent direct effects; values in parentheses represent indirect effects. ${ }^{*} \mathrm{p}<0.05 ;{ }^{* *} \mathrm{p}<$ $0.01 ;{ }^{* * *} \mathrm{p}<0.001$. 


\section{Result}

This paper develops a model used to examine the linkage among leader's verbal communication styles (autocratic and supportive verbal communication styles) work engagement, job burnout and job satisfaction. Our findings suggest the following main conclusions. First, leader's autocratic verbal communication style has negative relationships with job satisfaction; meanwhile, supportive verbal communication style appears to have a positive relationship with job satisfaction. Second, work engagement plays a partial mediating role in influencing the relationship between leader's two verbal communication styles and job burnout only has mediating effect between autocratic verbal communication style and job satisfaction.

In summary, leader's verbal communication styles have significant effects on job satisfaction, which imply that different leader's verbal communication styles contribute to employee's attitudes in the nature of both positive and negative direction. For instance, leader's autocratic verbal communication style may induce job satisfaction thus decreasing the organization's productivity, whereas the supportive verbal communication style can improve employee's job satisfaction thus leading to better organization's productivity. Nevertheless, the mechanism of those influences is mediated by work engagement and job burnout. These results suggest that more attention should be paid toward verbal communication style and supportive verbal communication style should be more excised by the organization's leaders, especially under the situation where the employees are sensitive to emotional reaction.

\section{Conclusions}

Our study contributes to the literature on leadership and communication theory. In previous study, few have attempted to operationalize the verbal communication styles leaders use in their contacts with subordinates and even fewer attempted to find out what the relations are of these verbal communication styles with outcome factors. The foregoing outcomes demonstrated that different leader's verbal communication styles could be able to result in high or low job satisfaction. Meanwhile, the mechanism of those influences is mediated by work engagement/job burnout, which has been confirmed for the first time. Practically, this may provide some guides and constructive suggestions for leader's verbal communication styles. Katz and Kahn (1978) think that the role of the leader is to provide the necessary incremental information, support, and resources, over and above those provided by the formal organization or the subordinate's environment, to ensure both subordinate satisfaction and effective performance [64]. As a key part of leader behavior, it is necessary for the organizational leaders to pay attention to the skills of the verbal communication. Compared with autocratic communication, supportive verbal communication style will be more useful in terms of increasing work engagement and decreasing job burnout thus leading to high job satisfaction and increasing more positive organizational behaviors. Although the study gives us some meaningful result, there are some gaps and inspiration we should note.

Firstly, is leader's verbal communication style really stable and habitual as Norton said? Dansereau, Graenand Haga (1975) in the Vertical Dyad Linkage (VDL) Model assumed that supervisors show considerable variability in their behaviors across subordinates [65]. Hence, dyadic superior-subordinates relationship was thought to be the appropriate unit of analysis. Our study overcomes this problem. But the verbal communication style measured is only an overall evaluation. The situational theorists think that the best leadership is dependent on the situational contingencies (Tannenbaum \& Schmidt, 1958) [66]. In fact, for effectiveness, leader's verbal communication styles may also change along with the stage of organizational development, communication situation, as well as the length of contact time, which were not considered in the research. Moreover, leader's verbal communication style is dynamic and changeable rather than static and stagnates. Besides, we characterized leader's verbal communication style into two categories, i.e., autocratic and supportive. It is no doubt that a multitude of verbal communication styles exists besides autocratic and supportive verbal communication styles. From the standpoint of Blake and Mouton, management is not just an addition of two types of behavior, but integration and synthesis of the two dimensions, expressing qualitatively different aspects in leaders' behavior (Blake \& Mouton, 1981, 1982a, 1982b) [67]-[69]. There could be interaction between the two dimensions where one facilitates the other. Thus, future studies should give more consideration of the leader's dynamic, changeable, various and multiple verbal communication styles and their effects on job satisfaction. Secondly, although there are many factors that can affect job satisfaction, our study just specifically chooses work engagement/job burnout as the mediating factor. It is instrumental that the future studies may introduce other factors in a modeling work. Thirdly, we should acknowledge that Norton's theory is conceptually strong, but when it comes to measurement, 
it is still crude to some extent, which can be seen in our factor analysis results. Applying Norton's CSM only be treated as a beginning, it is necessary to build a better way to measure communication style. At last, all target managers voluntarily participated in this study. Of the total of 400 managers, 163 chose not to participate. Those nonparticipants may represent a heavy concentration of "poor" communicators. Hence, the exclusion of these people from the sample could have affected the results. This problem should be avoided, if possible, in future. Needless to say that the small sample size utilized in this study may have a potential to cause some biased statistical test results.

\section{References}

[1] Jablin, F.M. (1979) Superior-Subordinate Communication: The State of the Art. Psychological Bulletin, 86, 1201. http://dx.doi.org/10.1037/0033-2909.86.6.1201

[2] Norton, R.W. (1978) Foundation of a Communicator Style Construct. Human Communication Research, 4, 99-112. http://dx.doi.org/10.1111/j.1468-2958.1978.tb00600.x

[3] Fleishman, E.A. and Hunt, J.G. (1973) Twenty Years of Consideration and Structure. Current Developments in the Study of Leadership: A Centennial Event Symposium Held at Southern Illinois University at Carbondale. Southern Illinois University Press, 1, 13-26.

[4] Burgoon, J.K., Buller, B.D. and Woodall, W.G. (1989) Nonverbal Communication: The Unspoken Dialogue. Harper \& Row, New York.

[5] Chaganti, V.K. and Bikkina, N. (2011) Leadership Theory from a Communication Style Perspective: A Critical Analysis. Editorial (ii). The Relationship between Accounting Earnings, Stock Return Sanjay J. Bhayani 1 Volatility and Corporate Disclosure Practices: Empirical Evidence from the Indian Corporate Leadership Theory from a Communication Style Perspective. Vinay Kumar Chaganti, 16, 16.

[6] Frese, M., Beimel, S. and Schoenborn, S. (2003) Action Training for Charismatic Leadership: Two Evaluations of Studies of a Commercial Training Module on Inspirational Communication of a Vision. Personnel Psychology, 56, 671698. http://dx.doi.org/10.1111/j.1744-6570.2003.tb00754.x

[7] Kirkpatrick, S.A. and Locke, E.A. (1996) Direct and Indirect Effects of Three Core Charismatic Leadership Components on Performance and Attitudes. Journal of Applied Psychology, 81, 36. http://dx.doi.org/10.1037/0021-9010.81.1.36

[8] Riggio, R.E., Riggio, H.R., Salinas, C. and Cole, E.J. (2003) The Role of Social and Emotional Communication Skills in Leader Emergence and Effectiveness. Group Dynamics: Theory, Research, and Practice, 7, 83. http://dx.doi.org/10.1037/1089-2699.7.2.83

[9] Shamir, B., Arthur, M.B. and House, R.J. (1994) The Rhetoric of Charismatic Leadership: A Theoretical Extension, a Case Study, and Implications for Research. The Leadership Quarterly, 5, 25-42. http://dx.doi.org/10.1016/1048-9843(94)90004-3

[10] Ganster, D.C. (1981) Leader Communication Style: Toward the Development of a Multi-Dimensional Model. 31st Annual Meeting of the International Communication Association, Minneapolis, 21-25 May 1981.

[11] Richmond, V.P. and Mccroskey, J.C. (1979) Management Communication Style, Tolerance for Disagreement, and Innovativeness as Predictors of Employee Satisfaction: A Comparison of Single-Factor, Two-Factor, and Multiple Factor Approaches. Communication Yearbook, 3, 359-373.

[12] Sorenson, R.L. and Savage, G.T. (1989) Signaling Participation through Relational Communication a Test of the Leader Interpersonal Influence Model. Group \& Organization Management, 14, 325-354. http://dx.doi.org/10.1177/105960118901400307

[13] De Vries, R.E., Bakker-Pieper, A. and Oostenveld, W. (2010) Leadership = Communication? The Relations of Leaders' Communication Styles with Leadership Styles, Knowledge Sharing and Leadership Outcomes. Journal of Business and Psychology, 25, 367-380. http://dx.doi.org/10.1007/s10869-009-9140-2

[14] Richmond, V.P., Mccroskey, J.C. and Mccroskey, L.L. (2001) Organizational Communication for Survival: Making Work, Work. Allyn and Bacon, Boston.

[15] Bradley, P.H. and Baird Jr., J.E. (1977) Management and Communicator Style: A Correlational Analysis. Communication Studies, 28, 194-203. http://dx.doi.org/10.1080/10510977709367940

[16] Dormann, C. and Zapf, D. (2001) Job Satisfaction: A Meta-Analysis of Stabilities. Journal of Organizational Behavior, 22, 483-504. http://dx.doi.org/10.1002/job.98

[17] Cranny, C.J., Smith, P.C. and Stone, E. (1992) Job Satisfaction: How People Feel about Their Jobs. Lexington Books, Lexington. 
[18] Locke, E.A. (1976) The Nature and Causes of Job Satisfaction. In: Dunnette, M.D., Ed., Handbook of Industrial and Organizational Psychology, Vol. 1, 1297-1343.

[19] Miner, J.B. (1992) Industrial-Organizational Psychology. McGraw-Hill Book Company, New York.

[20] Brief, A.P. (1998) Attitudes in and around Organizations. Sage, Thousand Oaks, 9.

[21] Weiss, H.M. (2002) Deconstructing Job Satisfaction: Separating Evaluations, Beliefs and Affective Experiences. Human Resource Management Review, 12, 173-194. http://dx.doi.org/10.1016/S1053-4822(02)00045-1

[22] Hoppock, R. (1935) Job Satisfaction. Harper, Oxford.

[23] Churchill Jr., G.A., Ford, N.M. and Walker Jr., O.C. (1974) Measuring the Job Satisfaction of Industrial Salesmen. Journal of Marketing Research, 11, 254-260. http://dx.doi.org/10.2307/3151140

[24] Arnold, H.J. and Feldman, D.C. (1986) Organization Behavior. New York, 1.

[25] Williams, L.J. and Hazer, J.T. (1986) Antecedents and Consequences of Satisfaction and Commitment in Turnover Models: A Reanalysis Using Latent Variable Structural Equation Methods. Journal of Applied Psychology, 71, 219231. http://dx.doi.org/10.1037/0021-9010.71.2.219

[26] Trice, H.M. and Beyer, J.M. (1993) The Cultures of Work Organizations. Prentice-Hall, Inc., Upper Saddle River.

[27] Richmond, V.P., Mccroskey, J.C., Davis, L.M. and Koontz, K.A. (1980) Perceived Power as a Mediator of Management Communication Style and Employee Satisfaction: A Preliminary Investigation. Communication Quarterly, 28, 37-46. http://dx.doi.org/10.1080/01463378009369380

[28] Mast, M.S., Hall, J.A. and Roter, D.L. (2007) Disentangling Physician Sex and Physician Communication Style: Their Effects on Patient Satisfaction in a Virtual Medical Visit. Patient Education and Counseling, 68, 16-22. http://dx.doi.org/10.1016/j.pec.2007.03.020

[29] Barlow, S., Hansen, W.D., Fuhriman, A.J. and Finley, R. (1982) Leader Communication Style: Effects on Members of Small Groups. Small Group Behavior, 13, 518-531. http://dx.doi.org/10.1177/104649648201300407

[30] Hampton, R., Dubinsky, A.J. and Skinner, S.J. (1986) A Model of Sales Supervisor Leadership Behavior and Retail Salespeople's Job-Related Outcomes. Journal of the Academy of Marketing Science, 14, 33-43. http://dx.doi.org/10.1007/BF02723262

[31] Kahn, W.A. (1990) Psychological Conditions of Personal Engagement and Disengagement at Work. Academy of Management Journal, 33, 692-724. http://dx.doi.org/10.2307/256287

[32] Maslach, C., Schaufeli, W.B. and Leiter, M.P. (2001) Job Burnout. Annual Review of Psychology, 52, 397-422. http://dx.doi.org/10.1146/annurev.psych.52.1.397

[33] Kahn, W.A. (1992) To Be Fully There: Psychological Presence at Work. Human Relations, 45, 321-349. http://dx.doi.org/10.1177/001872679204500402

[34] Rich, B.L., Lepine, J.A. and Crawford, E.R. (2010) Job Engagement: Antecedents and Effects on Job Performance. Academy of Management Journal, 53, 617-635. http://dx.doi.org/10.5465/AMJ.2010.51468988

[35] Bakker, A.B., Schaufeli, W.B., Leiter, M.P. and Taris, T.W. (2008) Work Engagement: An Emerging Concept in Occupational Health Psychology. Work \& Stress, 22, 187-200. http://dx.doi.org/10.1080/02678370802393649

[36] Maslach, C. (1993) Burnout: A Multidimensional Perspective. Professional Burnout: Recent Developments in Theory and Research. Taylorand Francis, Washington DC, 19-32.

[37] Maslach, C., Jackson, S.E. and Leiter, M.P. (1986) Maslach Burnout Inventory Manual.

[38] Maslach, C., Jackson, S. and Leiter, M. (1996) Maslach Burnout Inventory Manual. Consulting Psychologists Press, Palo Alto.

[39] Maslach, C. and Leiter, M.P. (1997) The Truth about Burnout: How Organization Cause, Personal Stress and What to Do about It. Jossey-Bass, San Francisco.

[40] Schaufeli, W.B. and Salanova, M. (2007) Work Engagement: An Emerging Psychological Concept and Its Implications for Organization. In: Gilliland, S.W., Steiner, D.D. and Skarlicki, D.P., Eds., Research in Social Issues in Management, Information Age Publishers, Greenwich, 135-177.

[41] Halbesleben, J.R. (2010) A Meta-Analysis of Work Engagement: Relationships with Burnout, Demands, Resources, and Consequences. In: Bakker, A.B. and Leiter, M.P., Eds., Work Engagement: A Handbook of Essential Theory and Research, Vol. 8, Psychology Press, New York, 102-117.

[42] Yousef, D.A. (2000) Organizational Commitment: A Mediator of the Relationships of Leadership Behavior with Job Satisfaction and Performance in a Non-Western Country. Journal of Managerial Psychology, 15, 6-24. http://dx.doi.org/10.1108/02683940010305270

[43] Simpson, M.R. (2009) Engagement at Work: A Review of the Literature. International Journal of Nursing Studies, 46, 
1012-1024. http://dx.doi.org/10.1016/j.ijnurstu.2008.05.003

[44] House, R.J. (1996) Path-Goal Theory of Leadership: Lessons, Legacy, and a Reformulated Theory. The Leadership Quarterly, 7, 323-352. http://dx.doi.org/10.1016/S1048-9843(96)90024-7

[45] Ambady, N., Laplante, D., Nguyen, T., Rosenthal, R., Chaumeton, N. and Levinson, W. (2002) Surgeons’ Tone of Voice: A Clue to Malpractice History. Surgery, 132, 5-9. http://dx.doi.org/10.1067/msy.2002.124733

[46] Noels, K.A., ClÉMent, R. and Pelletier, L.G. (1999) Perceptions of Teachers’ Communicative Style and Students’ Intrinsic and Extrinsic Motivation. Modern Language Journal, 83, 23-34. http://dx.doi.org/10.1111/0026-7902.00003

[47] Laschinger, H.K.S. and Finegan, J. (2005) Empowering Nurses for Work Engagement and Health in Hospital Settings. Journal of Nursing Administration, 35, 439-449. http://dx.doi.org/10.1097/00005110-200510000-00005

[48] Seeman, M. and Anderson, C.S. (1983) Alienation and Alcohol: The Role of Work, Mastery, and Community in Drinking Behavior. American Sociological Review, 48, 60-77. http://dx.doi.org/10.2307/2095145

[49] Bennett, R.J. (1998) Perceived Powerlessness as a Cause of Employee Deviance. In: Griffin, R.W., O’Leary, K.A. and Collins, J.M., Eds., Dysfunctional Behavior in Organizations: Violent and Deviant Behavior, Monographs in Organizational Behavior and Industrial Relations, Vol. 23, JAI Press, Stanford and London, 221-239.

[50] Cathcart, D., Jeska, S., Karnas, J., Miller, S.E., Pechacek, J. and Rheault, L. (2004) Span of Control Matters. Journal of Nursing Administration, 34, 395-399. http://dx.doi.org/10.1097/00005110-200409000-00004

[51] Macey, W.H. and Schneider, B. (2008) The Meaning of Employee Engagement. Industrial and Organizational Psychology, 1, 3-30. http://dx.doi.org/10.1111/j.1754-9434.2007.0002.x

[52] Brief, A.P. and Weiss, H.M. (2002) Organizational Behavior: Affect in the Workplace. Annual Review of Psychology, 53, 279-307. http://dx.doi.org/10.1146/annurev.psych.53.100901.135156

[53] Sonnentag, S. (2003) Recovery, Work Engagement, and Proactive Behavior: A New Look at the Interface between Nonwork and Work. Journal of Applied Psychology, 88, 518-528. http://dx.doi.org/10.1037/0021-9010.88.3.518

[54] Saks, A.M. (2006) Antecedents and Consequences of Employee Engagement. Journal of Managerial Psychology, 21, 600-619. http://dx.doi.org/10.1108/02683940610690169

[55] Schaufeli, W.B., Taris, T.W. and Van Rhenen, W. (2008) Workaholism, Burnout, and Work Engagement: Three of a Kind or Three Different Kinds of Employee Well-Being? Applied Psychology, 57, 173-203. http://dx.doi.org/10.1111/j.1464-0597.2007.00285.x

[56] Visser, M.R., Smets, E.M., Oort, F.J. and De Haes, H.C. (2003) Stress, Satisfaction and Burnout among Dutch Medical Specialists. Canadian Medical Association Journal, 168, 271-275.

[57] Podsakoff, P.M., Mackenzie, S.B. and Podsakoff, N.P. (2012) Sources of Method Bias in Social Science Research and Recommendations on How to Control It. Annual Review of Psychology, 63, 539-569. http://dx.doi.org/10.1146/annurev-psych-120710-100452

[58] Lewin, K. (1959) Psychologie Dynamique. Presses Universitaires De France, Paris, 196-227.

[59] Spector, P.E. (1985) Measurement of Human Service Staff Satisfaction: Development of the Job Satisfaction Survey. American Journal of Community Psychology, 13, 693-713. http://dx.doi.org/10.1007/BF00929796

[60] Schaufeli, W.B., Salanova, M., González-romá, V. and Bakker, A.B. (2002) The Measurement of Engagement and Burnout: A Two Sample Confirmatory Factor Analytic Approach. Journal of Happiness Studies, 3, 71-92. http://dx.doi.org/10.1023/A:1015630930326

[61] Zhang, Y.W. and Gan, Y.Q. (2005) The Chinese Version of Utrecht Work Engagement Scale: An Examination of Reliability and Validity. Chinese Journal of Clinical Psychology, 13, 268-281.

[62] Baron, R.M. and Kenny, D.A. (1986) The Moderator-Mediator Variable Distinction in Social Psychological Research: Conceptual, Strategic, and Statistical Considerations. Journal of Personality and Social Psychology, 51, 1173-1182. http://dx.doi.org/10.1037/0022-3514.51.6.1173

[63] Judd, C.M. and Kenny, D.A. (1981) Process Analysis Estimating Mediation in Treatment Evaluations. Evaluation Review, 5, 602-619. http://dx.doi.org/10.1177/0193841X8100500502

[64] Katz, D. and Kahn, R.L. (1978) The Social Psychology of Organizations.

[65] Dansereau, F., Graen, G. and Haga, W.J. (1975) A Vertical Dyad Linkage Approach to Leadership within Formal Organizations: A Longitudinal Investigation of the Role Making Process. Organizational Behavior and Human Performance, 13, 46-78. http://dx.doi.org/10.1016/0030-5073(75)90005-7

[66] Tannenbaum, R. and Schmidt, W.H. (1958) How to Choose a Leadership Pattern. Institute of Industrial Relations.

[67] Blake, R.R. and Mouton, J.S. (1981) Management by Grid® Principles or Situationalism: Which? Group \& Organization Management, 6, 439-455. http://dx.doi.org/10.1177/105960118100600404 
[68] Blake, R.R. and Mouton, J.S. (1982) A Comparative Analysis of Situationalism and 9, 9 Management by Principle. Organizational Dynamics, 10, 20-43. http://dx.doi.org/10.1016/0090-2616(82)90027-4

[69] Blake, R.R. and Mouton, J.S. (1982) Theory and Research for Developing a Science of Leadership. Journal of Applied Behavioral Science, 18, 275-291. http://dx.doi.org/10.1177/002188638201800304 